\title{
O luto antecipado diante da consciência da finitude: a vida entre os medos de não dar conta, de dar trabalho e de morrer
}

\author{
The anticipated grieving before the awareness of finitude: \\ life and the fear of "not being able to cope," \\ "giving too much trouble" and dying
}

Karla Cristina Giacomin ${ }^{1}$

Wagner Jorge dos Santos ${ }^{1}$

Josélia Oliveira Araújo Firmo ${ }^{1}$

${ }^{1}$ Núcleo de Estudos em Saúde Pública e

Envelhecimento. Centro de Pesquisa René Rachou. Av. Augusto de Lima 1715, Barro Preto. 30.190-002 Belo Horizonte MG.

kcgiacomin@hotmail.com
Abstract In their praxis, health professionals must deal with the grieving of patient, family and staff, but for the elderly anticipated grieving due to disease and the awareness of finitude can be as disturbing as the actual death of someone. This paper seeks to understand anticipated grieving in the interaction between old age and health-disease and disability processes from the viewpoint of the elderly in the community faced with their own finitude. This observational ethnographic study was conducted with 57 elderly people assisted by the Family Health Strategy. The collection and analysis of data in semi-structured interviews was based on the model of signs, meanings and actions. The final categories that were revealed were: experiences of death while alive; experiences of the elderly in health care; awareness of finitude and anticipated grieving that negate the meaning of life. In local culture aging is a disease, disability is "being unable to cope" with everyday activities, and "giving too much trouble" to others is worse than dying. The older they are, the greater the anticipated and real grieving and loss and awareness of finitude, which have been neglected in health care. Understanding this question is crucial for comprehensive and humane care of the elderly and their families.

Key words Anticipated mourning, Disability, Elderly, Finitude, Death, Health service
Resumo Em suas práxis, os profissionais de saúde são forçados a lidar com os lutos do paciente, da família e da equipe, mas para uma pessoa idosa, o luto antecipado devido a doenças e a consciência da finitude podem ser tão perturbadores quanto a morte efetiva de alguém. O presente trabalho objetiva compreender o luto antecipado, percebido na interação entre a velhice e os processos saúde-doença e incapacidade, na visão de idosos da comunidade diante da própria finitude. Este estudo etnográfico observacional, realizado com 57 idosos assistidos pela Estratégia Saúde da Família, teve a coleta e a análise de dados guiadas pelo modelo de signos, significados e ações, em entrevistas semiestruturadas, emergindo como categorias finais: experiências da morte em vida; experiências dos idosos na atenção à saúde; consciência da finitude e lutos antecipados que tiram o sentido da vida. Para a cultura local a velhice é uma doença; incapacidade é "não dar conta" de fazer atividades cotidianas e "dar trabalho" aos outros é pior do que morrer. Quanto mais velhos, mais lutos e perdas antecipados e reais; maior a consciência da própria finitude; realidade que tem sido negligenciada na atenção à saúde. Compreender essa questão é crucial para um cuidado humanizado e integral da pessoa idosa e das famílias.

Palavras-chave Luto antecipado, Incapacidade, Idoso, Finitude, Morte, Serviço de saúde 


\section{Introdução}

Por toda a história, a morte é um evento social fundante da humanidade. Em cada cultura, compreendida como um universo de símbolos e significados que permite os sujeitos de um grupo interpretar suas experiências e guiar suas ações ${ }^{1}$, rituais de luto têm facilitado a integração da morte, a transformação dos sobreviventes e a continuidade da vida dos seres humanos ${ }^{2}$.

No Ocidente, da Idade Média até a metade do século XX, geralmente, a morte acontecia em casa, junto à família, com taxas de mortalidade muito elevadas em todas as idades ${ }^{2}$, rituais de luto permitiam a quem sofrera a morte de um próximo afastar-se da vida, favorecendo o luto ${ }^{3,4}$. Porém, lentamente, a morte e o luto estão sendo dessocializados, desculturados e desritualizados ${ }^{5}$. Nossa sociedade experimenta uma hiperindividualização desse fenômeno ${ }^{2}$, com a perda de sistemas simbólicos que envolvem o acompanhamento, o morrer, a morte, o luto e o além da morte, deixando para cada um a iniciativa dessas significações ${ }^{4}$.

Esse vazio cultural coloca a cargo dos indivíduos a invenção, o sagrado, o respeito; enquanto a pessoa que vai morrer fica submetida ao silêncio, à infelicidade absoluta, à rejeição, à culpabilidade dos próximos, inclusive de equipes de saúde $^{3,5}$ despreparadas para lidar com a velhice, a fragilidade e a finitude humanas ${ }^{4}$. Ademais, enquanto a percepção da população (que orienta comportamentos) usualmente se liga a uma rede de símbolos que articulam conceitos biomédicos e culturais, a percepção dos profissionais (que geralmente orienta políticas de saúde) costuma hipervalorizar o saber biomédico em detrimento dos conceitos culturais trazidos pelos sujeitos ${ }^{5-7}$.

De modo muito oportuno, Gadamer analisou a profunda relação entre o saber da certeza da própria finitude e aquilo que ele denominou “o impetuoso e urgente não-querer-saber desse tipo de consciência" . Afinal, a morte permanece o principal tema tabu na cultura ocidental envolvendo dois processos: um intrapsíquico de negação e outro relacional de fechamento e solidão, que impede pessoas de comunicar o que pensam para não incomodar a família e os ou$\operatorname{tros}^{3}$, inclusive profissionais que lidam diuturnamente com esta realidade.

Atualmente, a simbologia que envolve a experiência da aproximação da morte pela pessoa que vai morrer e pelos seus próximos encontrase diluída e submetida ao extremo ao domínio tecnológico nas diferentes etapas do processo, sendo objeto de forte negação ${ }^{5}$, o que produz uma "desmitologização" da morte e da própria vida ${ }^{6}$. Essa aversão à morte e ao sofrimento, além de negligenciar a pessoa e a família enlutadas, compromete seu acompanhamento frente a perdas, antecipadas ou efetivas, que requeiram um luto que reconheça a desistência e transforme essa experiência, internalizando o essencial para seguir adiante ${ }^{3}$.

No Brasil e no mundo, o envelhecimento rápido altera o perfil de saúde populacional, prevalecem doenças crônicas e a morte entre os idosos ocorre em idades mais avançadas, repercutindo sobre o sistema de saúde, as famílias e os indivíduos $^{8}$. No plano dos significados, enquanto o imaginário se refugia no cenário narcísico superpotente que nega o luto das perdas progressivas na própria vida, a construção simbólica parece enraizada na disjunção entre vida e morte, confundindo sofrimento com gozo, risco de morrer com a "sensação" de estar vivo: a morte que não tem mais lugar invade toda a existência ${ }^{4,5}$. Assim, nutrindo uma falsa ideia de imortalidade, vivemos um tempo paradoxal em que conflitam o desejo de continuar vivo e o medo de envelhecer.

O presente trabalho visa colaborar para uma melhor compreensão do fenômeno da finitude humana, dando a conhecer aos profissionais e serviços de saúde a visão de idosos da comunidade acerca dos lutos que experimentam na vivência da velhice, da incapacidade e da proximidade da morte, contribuindo para a humanização e a integralidade do cuidado em saúde.

\section{Percurso metodológico}

Este estudo, de cunho antropológico, investiga o envelhecimento e a finitude, a partir da perspectiva êmica, na qual a pessoa é convocada a falar sobre a vida, sobre suas condições de saúde e sua inserção e interação no campo da saúde e sobre si. Esse mergulho no ambiente local e cultural do sujeito, onde ele se organiza e confere significados particulares à sua experiência, permite o conhecimento e a interpretação do fenômeno investigado a partir da visão do maior interessado - a própria pessoa idosa -, e não da visão do pesquisador ou da literatura ${ }^{8}$.

\section{Local e população de estudo}

Esta pesquisa foi conduzida na zona urbana de Bambuí, Minas Gerais. Sua renda advém da 
exploração de recursos naturais, em atividades como a extração mineral de caulim, a produção de cana-de-açúcar, grãos (café, arroz, milho, soja) e a pecuária leiteira ${ }^{9}$. Um terço de seus cerca de 23.000 habitantes se encontra em estado de pobreza, elegível para se cadastrar no Programa Bolsa-Família, mas nem todos obtiveram o benefício ${ }^{9,10}$

Similarmente ao ocorrido no Brasil, Bambuí passa por progressiva urbanização e envelhecimento. Em 1950, a população rural representava $84 \%$ da população total; em 2010: apenas 15\%. Quanto ao envelhecimento, em 1960,4\% dos habitantes eram idosos; em 2010: 16\%, em um ritmo superior ao do país?

A rede pública de assistência à saúde conta com seis Unidades Básicas de Saúde (UBS) que integram a Estratégia de Saúde da Família (ESF), um Centro de Saúde, uma unidade do Núcleo de Apoio à Saúde da Família, dois hospitais - um estadual e um municipal - e o Posto Avançado de Estudos Emanuel Dias (Fiocruz), que se destaca no controle da Doença de Chagas. Inexistem instituições de longa permanência para idosos ${ }^{11}$.

Para reconstruir o universo de representações (maneiras de pensar) e comportamentos ${ }^{12}$ (maneiras de agir) associados à incapacidade funcional foram selecionados idosos (> 60 anos) residentes em Bambuí. Visando assegurar a multivocalidade dos participantes, foram entrevistados homens e mulheres, de diversas idades e níveis funcionais, residentes no território das seis UBS e assistidos pela ESF. A identificação de aspectos operacionais de redundância e repetição de dados, fatores teóricos de consistência e representatividade de elementos associados à incapacidade e a qualidade das informações obtidas sobre funcionalidade contribuíram para a decisão de um determinado ponto de saturação amostral para regular o tamanho da amostra ${ }^{8}$.

\section{Coleta e análise de dados}

Estas etapas foram guiadas pelo modelo de signos, significados e ações, proposto por Corin et al. ${ }^{13}$ e oriundo da corrente interpretativa em antropologia ${ }^{1}$, em que emerge uma nova concepção da relação entre indivíduos e cultura. Ele parte do comportamento concreto dos indivíduos para reconstruir as lógicas conceituais subjacentes a seus comportamentos: as "maneiras específicas de pensar e agir"7.

$\mathrm{Na}$ coleta de dados, uma entrevista semiestruturada foi realizada no domicílio do participante, permitindo a ampliação do seu campo de fala. Procurou-se investigar a avaliação da própria saúde e da funcionalidade de cada idoso(a), a partir da descrição do seu cotidiano, por meio das seguintes perguntas geradoras: a) Como você acha que está sua saúde? b) Para você, o que é uma saúde boa? E saúde ruim? c) Como é seu dia-a-dia, sua rotina? Como é um dia em sua vida? Com base nas respostas obtidas, outras perguntas foram feitas de maneira aberta abordando o contexto biopsicossocial, os recursos, o impacto e o significado da incapacidade.

Após as transcrições das entrevistas, várias leituras foram feitas e cada entrevista fragmentada para identificar frases, palavras, adjetivos, concatenação de ideias, sentido geral do texto ${ }^{14}$, que tratassem das unidades de significado: saúde, doença e incapacidade e sua relação com o tema morte. Estes signos - suas explicações privilegiadas; as ações desencadeadas bem como o impacto específico de diferentes elementos dos contextos pessoal, social e cultural na construção e na evolução das reações e dos comportamentos $^{14}$ - possibilitaram estabelecer várias categorias empíricas para, finalmente, compreender as ações e as falas dos sujeitos diante da realidade vivenciada em relação à velhice, à incapacidade e à morte. Para assegurar o anonimato dos entrevistados cada um foi identificado pelo sexo ( $\mathrm{M}$ para mulher ou $\mathrm{H}$ para homem) e pelo número de sequência de realização da entrevista.

\section{Aspectos éticos}

Esta pesquisa, parte do projeto "Abordagem antropológica da dinâmica da funcionalidade em idosos", foi aprovada pelo Comitê de Ética do Centro de Pesquisa René Rachou/Fiocruz. As entrevistas foram realizadas mediante consentimento livre e esclarecido dos idosos, em acordo com a Resolução no196/1996 do Conselho Nacional de Saúde ${ }^{15}$.

\section{Resultados e discussão}

Foram entrevistados 57 idosos (27 homens e 30 mulheres) com idades entre 62 e 96 anos. Quanto ao estado civil, 24 eram casados; um vivia em união estável; sete eram solteiros; e 25 estavam viúvos. A maioria deles teve filhos. No grupo, predominam a religião católica, a baixa escolaridade e a origem rural, sendo motivos de mudança para a cidade a proximidade com o serviço de saúde e/ou com a escola para os filhos. Todos os participantes responderam a questões referentes 
às suas percepções de saúde e ao seu cotidiano. $\mathrm{Na}$ análise final, na interação entre envelhecimento, saúde, doença e incapacidade, três categorias emergiram: Experiências da morte em vida; Experiências na atenção à saúde e a Consciência da finitude e dos lutos antecipados que tiram o sentido da vida.

\section{Experiências da Morte em Vida}

A entrevistada mais velha do grupo narra seu momento de vida: Muita idade... Não dou conta mais [...]. Quase não escuto. [...] Labirintite, que eu sofro. E também glaucoma no olho [...] catarata. Enxergo, mas pouco, né? [...] Fico muito sozinha, que a familia tudo precisa de cuidar do que é deles e... na minha saúde, eu ficava sozinha, trabalhava sozinha. [...] foi acabando e acho que ficou desse jeito (M16, 96 anos, viúva). Neste relato, o signo na minha saúde reflete o tempo ativo da juventude, da vida adulta, do trabalho, configurando uma ideia assimilada no grupo de que a saúde ficou no tempo passado da memória.

Duas idosas definem: Eu acho que não tem idade pra falar, aquela pessoa tá velha não. Ela tendo saúde, ela não pensa que tá velha. [...] Se ela sente bem, se ela come bem, se ela dorme bem, se ela anda, se ela conversa com todo mundo, ela tá disposta pra tudo... [...], menos pras outras coisas, menos aquelas, se você me entende [risos]. Que essas já passou, né? [risos] [...]. Pra mim já passou. Agora se a pessoa se entregar, ela mesmo: 'tô velho, tô velho, tô velho', aí fica velho.(M5, 77 anos, viúva); e Já fiz muitos exames, já fiz três raios-X, não acusa nada e nem vai acusar que isso é velhice né [risos]. [...] Gente, as mulher tão ficando tudo velha! 'Tô com isso, tô com aquilo'. Gente, isso é velhice! 'Que doença que é a da sua mãe'? É velhice! (M19, 83 anos, viúva).

No grupo, envelhecer remete a: desistência, falta de disposição, fim da atividade sexual, doença. Assim, uma pessoa idosa sem sintomas permanece jovem, como se a juventude fosse uma qualidade moral ${ }^{16}$. Se, por séculos, as sociedades tradicionais integravam e valorizavam a sabedoria e a experiência de pessoas mais velhas ${ }^{1}$, as sociedades atuais, voltadas ao culto da juventude ${ }^{16}$, recusam a normalidade da velhice, a ponto de considerá-la uma doença. O estereótipo atual do velho é o de alguém doente, impotente, dependente, sem a dignidade de um ser humano forte e livre; porém, ao negar as diferenças e a realidade que poderia ser a nossa, nega-se a própria vida ${ }^{17}$.

Uma viúva, sem citar a morte, diz: muita recordação porque a vida é boa, mas você tem que tá com saúde. Se você tiver doente não presta: o quê que adianta cê ter dinheiro, cê ter roupa boa, sapato bom e lelé deste jeito? Não adianta, é preferível... [...] a gente não podia comprar nem $1 \mathrm{~kg}$ de carne para comer, mas a gente tinha saúde, tava boa. Vestia uma roupa usada que os outros davam, mas não tava sentindo nada. Agora hoje, você pode ter tudo, mas tá doente, não adianta não. (M24, 86 anos, viúva). A desigualdade social e experiências difíceis no ciclo da vida compõem as condições da velhice atual ${ }^{18}$. Na saúde, a pessoa experimenta um estado de inconsciência sobre o seu corpo; a doença sinaliza para o sujeito sua corporeidade ao extremo ${ }^{6}$ e por isso mesmo sua velhice - etapa final da vida ${ }^{4}$.

Ao falar sobre o cotidiano, duas mulheres relatam condições distintas: A cada dia que passa, a gente aparece com uma coisa, mas não é coisa assim grave, importante não. Sempre a gente dá conta da obrigação da gente. Não é igual era no princípio, mas dá conta. (M5, 77 anos, viúva); e Não dou conta de fazer nada não. Nem assim de noite, de modo de eu cobrir, não dou conta de puxar um lençol pra me cobrir com a mão. (M8, 83 anos, viúva). Nas falas, o signo dar conta de fazer algo se refere à funcionalidade e não dar con$\mathrm{ta}$, à incapacidade funcional, mas os respectivos conceitos biomédicos não foram identificados nem reconhecidos pelos participantes.

Dois homens reconhecem: Não tenho medo da morte não. Se falar assim: 'vai morrer amanhã', não tem problema. Eu tenho medo é de, por exemplo, eu sou assim, um pouco agitado, se eu cair numa cama e não puder andar, um trem assim, aí eu tenho medo, de ficar dando trabalho pros outros, ficar pela mão dos outros. Ai é preferivel que a gente morresse [risos] (H18, 65 anos, casado) e Eu detesto ver uma pessoa pedindo 'por favor, por caridade, pelo amor de Deus', pra fazer certas coisas que eu não faria. Você me desculpe a expressão: 'limpar a bunda'. Acho que é uma coisa chata pra fazer isso pra gente. Mas o quê que pode fazer? Chegar nesse ponto... Paciência. Deus sabe o que faz, né? (H15, 79 anos, casado). Outra mulher admite: quando dá derrame e não morre, perde uma parte do corpo, aí não dá conta de andar mais, vai pra cadeira de rodas, fica na mão dos outros. [...] É muito triste! Coitada daquela pessoa que tá ali... Às vezes perde a fala, não pode nem falar mais com aquela pessoa que tá cuidando. [...] Tanta gente perde a paciência! (M4, 81anos, viúva).

Nessas falas, dar trabalho aos outros significa precisar da ajuda de alguém e atemoriza mais do que a morte. Diante da ameaça de perdas a curto, médio e longo prazo, as pessoas que cuidam - 
familiares ou não - podem se tornar superprotetoras, vigilantes, irritadiças, hesitantes ou arredias, alternando sentimentos de culpa, tristeza, raiva, solidão, ressentimento, exaustão, desespero ${ }^{4}$.

Outra mulher reflete: No que é bom ter 89 anos? Ah, eu acho bom, se eu não cair na cama e ficar dando trabalho. Eu peço a Deus e que quando Ele for me tirar, que me tire assim depressa, sabe? Eu tenho dois lugar lá no cemitério: o do meu pai e o do meu marido (M1, 89 anos, viúva). Assim, consciente da sua finitude, ao falar do lugar da sepultura - um dos critérios de humanidade esta mulher muito idosa atesta "a antiguidade e a persistência deste fato [?]: não nos desfazemos dos mortos, nunca nos livramos deles"19.

Perguntado sobre o que acha ser mais difícil ficar sem fazer uma coisa ou precisar de alguém - um idoso pondera: $A h$, isso, todos os dois é ruim. A gente não dar conta de fazer e precisar dos outros. (H30, 76 anos, solteiro). Neste e em outros estudos $^{4,16,20}$, percepções negativas da velhice relativas às perdas, temidas ou reais, da autonomia, do controle, da independência, da capacidade para o trabalho, reforçam a cultura ocidental para a qual envelhecer pode ser pior que morrer ${ }^{4,21}$. Ademais, pessoas idosas, particularmente as mais frágeis, muitas vezes manifestam o luto na saúde física, no equilíbrio psicológico e em comportamentos de risco ${ }^{4}$ e procuram por cuidado na atenção à saúde.

\section{As experiências dos idosos na atenção à saúde}

Um homem relata: Minha saúde, desde a infância, eu venho lutando com certos, com muitos tipos de doenças, inclusive, de novo, desde os 11 anos de idade, eu já comecei com um tipo de reumatismo. [...] fiz três cirurgias [...] [a artrite] pegou a cervical, pegou a coluna toda. O único lugar que não me pegou foi aqui no braço. [...] tenho diabetes tem mais ou menos uns 25 anos e de dois anos pra cá, depois que sofri o infarto, o médico [...] passou pra insulina. [...] O médico achou que eu tava com o rim tão ruim que cheguei a implantar uma fístula pra hemodiálise, mas, graças a Deus, não foi preciso ainda. [...] Há 5 anos, tive duas úlceras varicosas nos dois pés, [...] me causou aí uns 7 meses de cama [...] quando fui pra Belo Horizonte, já fui ruim, tive que fazer três depuragens em cada pé e depois fazer enxerto [...] tem uns três anos que eu tô de muleta por causa desse joelho, que a perna entortou demais [...] então tô aguardando... [a cirurgia]. (H43, 62 anos, em união estável).
Uma idosa descreve a explicação recebida sobre o tratamento: Essa perna aí, eu tive que fazer enxerto [...] eu machuquei, teve que cortar, né, aí eu fiquei... pelejando, né? Ia e voltava. Não pegava [o enxerto]. Tornava a ir e não pegava. Depois o doutor falou assim: 'agora você vai ficar aí e nós vai fazer um serviço pra valer'. E fez mesmo! Aí cortou a carne da perna tudo, que tinha que cortar, senão dava câncer né (M8, 83 anos, viúva).

Embora nesses relatos os profissionais tenham buscado resolver os problemas, nota-se um olhar fragmentado do profissional e do serviço ao assistir uma pessoa idosa. Possivelmente isso reflita a formação recebida e o desconhecimento de que, também na velhice, a saúde requer um cuidado integral ${ }^{6}$, que incorpore questões relativas à subjetividade e outras específicas oriundas do próprio processo do envelhecimento humano, vivenciadas no meio sociocultural e na história de vida do sujeito.

Homens buscam cuidados: [o médico] só falou comigo assim: 'o senhor não preocupa muito não, caça um jeito de ficar mais despreocupado, repouso, isso maior que você sente agora é idade. Essa idade da gente aparece uma coisinha aqui, aparece outra por lá, o senhor não tem que preocupar, não'. (H7, 84 anos, casado); e É meio sem recurso, porque a coluna não sara, cuidando a tempo conserva, conforme a vez que dá, melhora, mas sarar não sara não. [...] Quantos anos que isso tá me acompanhando! Agora é convencer como que tá, repouso, ficar quietinho e usar os remedinhos. É isso aí. [H36, 84 anos, casado]; e Vou ao médico diário [...]. Dá aquela perrengada, ele [o médico] arranja aquele remédio e fala: 'Cê leva esse e vai tomando, acaba uma receita e pega outra e, na hora que piorar mais, cê volta. (H23, 82 anos, casado, grifo nosso). Outra mulher reproduz e interpreta o que ouviu: O médico falou [...] que eu constipei os ossos. Agora não tem jeito, não. [...] O médico não cura. É igual lenha. Lenha secou, complica, né? (M8, 83 anos, viúva).

Importante compreender que tudo o que for efetivamente dito, insinuado ou mal esclarecido será interpretado: as pessoas e famílias escutam por meio de filtros históricos, culturais, étnicos muito diferentes ${ }^{5,12-14,22}$. Logo, a experiência da doença não pode ser considerada um simples reflexo do processo patológico no sentido biomédico do termo; e sim uma construção cultural expressa em "maneiras específicas de pensar e agir"7. O saber profano dos entrevistados obedece à sua visão do mundo para dizer dos sofrimentos ou surpresas que o corpo revela, mas a medicina "não escuta deste ouvido, pois partici- 
pa de uma cultura sábia, própria a um grupo restrito" com outros valores e conhecimentos ${ }^{19}$. A língua do médico não é a de quem vive a experiência corporal, imersa em atitudes e valores culturais próprios, que a cultura médica desconhece ${ }^{12-14,19,21,22}$.

Uma idosa reflete: Eu penso assim: o que for para mim, Deus me dá, porque não adianta eu falar que eu não vou querer. Ele pode me dar um câncer, ele pode me dar uma doença que eu nem estou pensando. (M5, 77 anos, viúva). Ainda assim, uma mulher faz tudo o que lhe é recomendado porque: Eu acho que não vou viver muito mais não. [...]. Tenho dó dos meus filhos porque eles já perdeu o pai. Muita coisa eu faço por eles: eu falo assim: [...] vou tomar esse tanto de remédio, a mão cheia de remédio de manhã e vou alimentar direitinho as coisas que eu posso, pra não fazer mal pra diabetes. Que eu tenho dó. Se eu for, pra mim não tem importância, e pra eles né? (M51, 69 anos, viúva).

Logo, conscientes de uma finitude cada vez mais próxima ${ }^{4}$, percebida no corpo-vivido, os idosos procuram os serviços na esperança de minimizar sofrimentos próprios e alheios, sejam eles de fundo moral, espiritual, físico, psicológico e ou funcional. Mas recebem a notícia de que nada há a ser feito, pois o profissional reproduz a concepção do saber biomédico e culturalmente assimilada pelos idosos, que compreende o processo velhice-doença-incapacidade como coisa da idade, portanto, inexorável e sem recurso ${ }^{22}$. Assim, o cuidado integral resta comprometido pelo despreparo do profissional em lidar com situações incuráveis e demandas reveladoras da finitude humana.

\section{A consciência da finitude e os lutos antecipados que tiram o sentido da vida}

Uma viúva responde se gosta de ter 81 anos: Uai, Deus quis assim né?... [Incomoda?] Não, não incomoda, não. Eu até falei que não queria ficar velha não, mas tô ficando velha demais. Quando eu era mais nova, eu falava: não quero morrer velha! Já tô ficando velha demais! [Por quê?] $A h$, dá trabalho! [A senhora dá trabalho pra alguém?] Ah, o povo não acha, mas a gente acha. (M4, 81 anos, viúva).

Um homem comenta: 72 anos sem tomar um comprimido é muito prazer na vida, não? De dois anos pra cá, emperrenguei. [...] Internei em outra cidade, fiquei lá 22 dias. Não fez cirurgia, não fez nada. Vim embora [...]. Uai, mudou que a gente fica mais nervoso porque fica pensando mais nas doenças. Até que quando você não tá sentindo nada você não pensa. [...] Adoeci, nós achou que era um infarto, [...] até que fez os exames, o eletro, aí eles falou que o músculo do meu coração cresceu. A gente quando é muito novo faz muita força, então ele cresce. E a gente não tratava. Não sentia nada, como é que vai tratar? Mas isso não tem nada a ver não. Fico em paz, faço o acompanhamento certinho, tomo os remédios certinho, venho cá de quatro em quatro meses. (H25, 74 anos, casado). Assim, ao lidar com doenças crônicas, o doente tem de aprender a aceitar a doença e a viver com ela ${ }^{6}$.

Outra mulher teme a hereditariedade de sua doença, a retinose pigmentar: Graças a Deus, adoeci e não pegou nas minhas filhas e eu espero também que não pega nos meus netos né? [...] Rezo muito, peço a Deus, porque essa doença pode dar em geração depois de eu. [...] Agora, acredito também que se aparecer nos meus netos, já tem mais recurso. Eu espero. (M44, 69 anos, desquitada). Portanto, a perda, efetiva ou antecipada, que a doença representa ou o medo de sua repetição na família sobrepõe o ciclo de vida da doença aos da família e do indivíduo, mas o impacto varia conforme a doença, a evolução, as exigências psicossociais ao longo do tempo, o grau de incerteza do prognóstico e as experiências transgeracionais familiares ${ }^{4,23,24}$. Muitas vezes, a procura pelo cuidado vincula-se à presença de sintomas, e a preocupação com a perda futura, que não existia, insere-se, de formas sutis e disfarçadas, no planejamento do ciclo da vida de quem convive com doenças crônicas. Perdas antecipadas são vividas concreta e subjetivamente: na família, no próprio corpo, no trabalho, nos projetos, no afastamento de pessoas, na falta de perspectivas de melhora. A cada piora, um luto intenso pode ocorrer em relação às oportunidades e experiências que serão definitivamente abandonadas ${ }^{23-25}$.

Um homem reconhece: Às vezes você não quer olhar [a morte], mas não tenho medo não. Chegou a hora, vai mesmo [Tem medo de dar trabalho?] Esse eu tenho medo, mas eu rezo e peço a Deus: 'vai me conformando até eu...' Eu mesmo tomo meu banho, eu mesmo calço... eu mesmo saio, eu mesmo mudo a minha roupa, mas ficar na cama, sem esperança de melhorar, sem esperança de morrer... (H25, 74 anos, casado). Outra idosa, sem filhos na cidade, com obesidade mórbida e cujo único movimento que realiza sozinha é abrir e fechar uma janela com uma bengala, pergunta se Deus se esqueceu dela e explicita seu desejo de morrer: O corpo dói, as pernas doem, fico cansada. Acho que Deus esqueceu de mim. Você acha que esquece? [...] Tenho de dar conta de aguentar, até Ele me levar. Vontade de ir para o céu (M34, 80 
anos, viúva, grifo nosso). Após sofrer um "derrame", esta mulher lamenta: Eu não quero [viver muito]. Para dar este trabalho todo? Ficar livre é melhor, né? [...] Um dia eu fiquei tão ruim que eles me levou para o... [referindo-se ao hospital], [me pôs] aqueles balão, eu voltei. [...] Mas fazer o quê, eu não posso me matar. Tenho que esperar Deus... consulto diariamente porque não sara, mas a gente fica naquela fé que vai sarar, mas o médico ótimo me desanimou que isso é idade, que eu tenho que aceitar... Mas fazer o quê, eu não posso me matar. Tenho que esperar Deus. Cê vê: a gente nascer perfeito e morrer aleijado? É triste, eu acho. [...] É difícil. Não é fácil não (M24, 86 anos, viúva, grifos nossos).

Portanto, a consciência da própria finitude e o luto antecipado serviriam para significar a morte, pois, em suas falas, a vida nestas condições perde o sentido e o valor ${ }^{6}$, enquanto a morte liberta a pessoa que precisa de cuidados de males, dores, sofrimentos de uma vida dependente, indesejada e de se julgar um peso para os outros, situação de tal modo difícil que os leva a pensar em pôr fim à vida ${ }^{26}$. Se a única alternativa é a morte, mas ela só vem quando Deus quer, na fé os entrevistados buscam forças para rechaçar a ideia do suicídio e suportar a vida na velhice-doença ${ }^{27}$.

Uma mulher que mora sozinha com Deus admite: Tenho medo de morrer e ficar aqui, morta aqui, sozinha. Tenho, porque as minhas vizinhas são muito boas, mas cada uma tem sua obrigação. [...] Se eu morrer de manhã ou de noite, eles vai levar uns três dias pra eles me achar [risos] (M48, 77 anos, viúva).

Ainda que não conte com os mesmos apoios nem com as ancoragens de responsabilidades familiares, profissionais ou eventualmente associativas, a velhice não significa necessariamente o luto da juventude ${ }^{16}$, e caso a pessoa saiba e possa se adaptar às novas condições de vida ${ }^{4}$, aceitar a própria morte é parte de uma velhice boa ${ }^{24}$.

Quanto ao luto de entes queridos, uma mulher relata: Ele [o marido] teve um problema de uma cólica e um rim dele morreu, sabe, e o doutor tirou um rim dele, então ele só tem um. Não pode trabalhar. Depois que eu perdi meu pai, minha mãe, um irmão mais velho meu, uma irmã mais nova que eu, eu fiquei muito triste. Então... tem época que eu fico pensando: ah meu Deus! Que vida ruim, sem o meu pessoal né? [...] Agora, minha filha, eu tô morando aqui na cidade e aquié um barulhão [...] difícil pra dormir de tanto barulho. Mas eu gostaria muito da roça! Ela [a patroa] morreu no ano passado. [...] O marido dela morreu tem pouco tempo. Vai morrendo, a gente fica numa tristeza! Há pouco tempo morreu muita gente aqui perto de casa, meus amigos, comadre minha, filha dela. Morreu uma mulher com 89 anos. Essa eu queria que ela morresse primeiro que a filha dela. Que ela tava pedindo muito a morte, ela não tava andando mais, ela tava muito velhinha. Uma filha dela que tinha 53 anos, deu um câncer na menina. [...] três meses, ela morreu. (M32, 73 anos, casada). Esta mesma senhora ainda sofre de uma doença endêmica e potencialmente letal: Sou chagada [há] muitos anos. Eu tinha 7 anos, agora pra você vê, eu tenho 73, né? É muito anos. Eu acho que de Chagas já passou o tempo de morrer, né? [...] Eu vou morrer de outra coisa. De Chagas é até 30 anos, né? (M32, 73 anos, casada).

Assim, quanto mais velhos, mais a imagem, a presença, a certeza da morte é inegável ${ }^{4}$. Portanto, podemos reprimir a morte na consciência, jamais eliminá-la ${ }^{6}$. Além disso, cada morte e cada perda vivida no corpo, na família, na mudança para a cidade, no barulho da rua, no falecimento dos patrões e em mortes de pessoas próximas - novas e velhas - e a perspectiva da própria morte, requerem diferentes lutos.

Outra mulher fala: Chagas, o meu médico mesmo falou que é uma doença ingrata: pode viver muitos anos e pode cair duma vez, como aconteceu com minha irmã mais velha. Ela veio jantar e caiu. [...] Meu irmão, que morreu mais novo, ele morreu com 29 anos. Depois essa mais velha morreu com 36. Tem uns 12 anos por aí, morreu um com 58, problema de Chagas. Eu já tô com 72, já tô ganhando. (M10, 72 anos, casada). Esta consciência objetiva, subjetiva e temporal da finitude anuncia o destino irrefutável de todo ser humano: o devermorrer-um-dia, ainda que não saiba como, nem quando $^{19}$. Mas essa condição não é exclusiva da doença de Chagas, afinal, a mais crônica de todas as doenças é encontrar o caminho da morte e a mais elevada tarefa humana, aprender a aceitar esse nosso mais amplo destino ${ }^{6}$.

Uma idosa se espanta: Parece que passou sem a gente ver, sabe. Passou esses 93 anos, eu falo assim: gente, será impossível que eu tenho essa idade? Será que tô registrada errada? Porque a minha vida foi tão boa, meu marido tão bom pra mim! [...] Nós viveu quase 53 anos! Ele morreu novo [...] tinha diabetes e deu problema de coração né, deu derrame e morreu. (M35, 93 anos, viúva). Outra mulher fala da viuvez: Fiquei muito abatida, [...] não esperava de jeito nenhum. Meu marido em plena saúde, fazendo caminhada, a bicicleta mandou ele longe, ele bateu com a cabeça, ficou três meses em Belo Horizonte e morreu em casa. [...] Às vezes, sonho com ele, sonho que a gente tá nos lugares que a gente 
ia, eu acordo feliz [risos], acordo muito feliz, porque eu sonho com ele não é morto e nem doente. Eu sonho com ele vivo. (M51, 69 anos, viúva).

A perda do cônjuge representa um dos acontecimentos mais importantes da vida: aquele com quem ou contra quem construímos nossa existência não existe mais ${ }^{25}$. A perda da vida de casal influi no funcionamento daquele que fica, reforçando componentes afetivos, securitários, estruturantes, de caráter positivo - de retribuição de cuidado ou de libertação de alguém que oprime - ou negativo - de falta ou amputação de uma parte importante de $\mathrm{mim}^{25}$. Expressando seu grande amor, esta mulher relata seu sofrimento: Eu perdi meu companheiro passou para três anos. Companheiro de 62 anos. [...] Levou uns seis anos [para morrer]. Foi o amor da minha vida. [...] E a gente sofre quando perde também, igual eu perdi né? A gente sofre, a gente é humano né? mas fazer o quê? (M58, 87 anos, viúva). Logo, mesmo considerada "normal" nos velhos e "incompreensível" em jovens, na prática, para todos, a morte pode parecer injusta e inesperada ${ }^{4}$.

Outra esposa-cuidadora descreve o lento e penoso adoecimento do marido: Sofreu demais, mas morreu [com dignidade], com 86 anos, com a cabeça boa, sabe, não ficou esclerosado, mas ele tinha cirrose, depois enfisema. [...] Outra hora ele já falava que não queria morrer, mas na véspera de morrer, na hora que eu fui com ele correndo para o hospital, [...] ele falou que queria morrer em casa, que não queria ficar em hospital com oxigênio e tal, mas eu tive que levar porque ele sentiu uma dor muito forte no abdome. Ele viveu 86 anos, foi pena que ele sofreu muito, mas, quer dizer, isso aí a gente não pode escolher. Aparece. Não é escolha da gente. [...] Fez muitas cirurgias que ele teve um câncer de boca. Aparece, tira. Apareceu outro, não é agressivo, nem dá metástase. Operou oito vezes. [...] Deu infecção, sarou. Depois, parece que ele teve um pequeno AVC [...]. Ele ficou de cama poucos dias, mas no fim eu levava tudo pra ele no quarto: comida, ele tomava banho sozinho - eu ajudando, segurando e firmando. Ele tomava banho, mas eu olhei ele até a última hora. (M33, 74 anos, viúva).

Dessa forma, se envelhecer nos confronta muito mais ao luto, podemos esperar gozar de mais maturidade para afrontá-1o ${ }^{4}$, pois sobreviver à morte de alguém é um longo processo, doloroso e catalisador de amadurecimento ${ }^{25}$. O luto significa uma provação da vida ${ }^{3,25} \mathrm{e}$ a questão da dignidade na morte revela-se na dependência dos outros, na indiferença ou incômodo, no cansaço mesmo que a pessoa que vai morrer sente ao seu redor ${ }^{21}$.
No campo de fala dos idosos, notam-se muitos lutos e perdas: do ser amado, da família, do ideal de si mesmo, parar de trabalhar; ter de abandonar atividades prazerosas; aposentar-se; sentir-se preso em casa por falta de acessibilidade ou por causa da violência urbana, do sentido da vida, do futuro, sem vislumbrar um objeto-auxílio em que investiri, ${ }^{3,420,23-28}$. Perguntada sobre o que poderia melhorar, esta mulher sintetiza: $A h$, tem: amor. (M24, 86 anos, viúva).

A maioria dos estudos sobre perdas antecipadas concentra-se nas doenças terminais; nelas, há uma linha do tempo de pontos nodais potenciais de perda que inclui a incapacidade e a morte. Também na velhice, a fronteira entre as fases crônica e terminal de uma doença é ambígua, sendo importante cambiar as esperanças de cura em um plano humanitário de cuidados paliativos, instilar esperança no desenvolvimento de um caminho para a morte e reduzir a lacuna que essa perda demarcará ${ }^{4,24}$. O acompanhamento e a partilha de responsabilidades se tornam a única possibilidade de uma relação incessantemente renovada pela perspectiva de acolher a morte, para médicos, cuidadores e pessoas, cujos pontos de convergência transformam a provação de uns na justificativa de ação dos outros, em uma semântica plural, que engloba diversos registros de interpretação $0^{24}$.

No grupo pesquisado, o modelo desejado de morte é a morte súbita, sem sofrimento e sem dar trabalho. Nas falas dos idosos, ao buscar o sistema de saúde, face às demandas de uma pessoa idosa enlutada, são aconselhados pelo profissional a se resignar diante das coisas da idade. Fica a impressão de que a pessoa idosa está desamparada nessa sociedade que não acredita nem oferece respostas para o desafio que representa envelhecer precisando de cuidados ${ }^{27,28}$.

\section{Considerações finais}

Ao envelhecer, o encontro com a morte se dá de modo repetitivo: na família, na vizinhança, na vida. Mas a morte também é vivida no próprio corpo, antecipadamente enlutado - machucado, limitado, mutilado, impedido de trabalhar e de fazer o que deseja ou gosta. Diante da consciência da própria finitude, na interação dinâmica do processo saúde-doença-velhice, o luto antecipado do sujeito idoso revela-se na convivência com doenças crônicas e incapacitantes e nos medos de não dar conta, de dar trabalho e de morrer. Face às falas, ao buscar atenção e cuidado nos 
serviços de saúde, os entrevistados recebem um cuidado fragmentado, restrito à(s) parte(s) doente(s) do corpo e produtor de uma cultura de conformismo e resignação - por parte do sujeito idoso e do profissional que o assiste. Ao cuidar de pessoas idosas, é necessário oferecer recursos que ultrapassem essa visão tecnicista, pessimista e limitada. O profissional de saúde deve agregar habilidades à sua práxis cotidiana que lhe permitam compreender a complexidade do processo saúde-doença-incapacidade na velhice e os medos a ele relacionados, bem como à perda em si, pois, o "se", o "como" e o "quando" do envelhecer, do morrer e da morte têm grande impacto sobre todos os envolvidos.

\section{Colaboradores}

KC Giacomin, WJ Santos e JOA Firmo participaram igualmente de todas as etapas da elaboração do artigo. 


\section{Referências}

1. Geertz C. A Interpretação das Culturas. Rio de Janeiro: Livro Técnico e Científicos Editora; 1989.

2. Ariès P. Sobre a História da Morte no Ocidente desde a Idade Média. Lisboa: Editorial Teorema; 1975.

3. Berthod MA. Entre psychologie des rites et anthropologie de la perte. Journal des anthropologues [En ligne], p. 116-117 2009, mis en ligne le 01 juin 2010, consulté le 22 mars 2013. Disponível em: http:// jda.revues.org/3432

4. Hanus M. Les deuils au grand âge. Études sur la mort 2009; 1(135):89-97.

5. Le Breton D, Ragi T. Mort et construction identitaire des jeunes. Agora - Débats / Jeunesses. Les jeunes face à la mort 2003; 34:14-20.

6. Gadamer HG. O caráter oculto da saúde. Petrópolis: Editora Vozes; 2006.

7. Uchôa E, Firmo JOA, Lima-Costa MF, Corin E. An anthropologic study on strategies for addressing health problems among the elderly in Bambuí, Minas Gerais State, Brazil. Cad Saude Publica 2011; 27(Supl. 3):S370-S377.

8. Turato ER. Métodos Qualitativos e Quantitativos na Área da Saúde: Definições e seus Objetos de Pesquisa. Rev Saude Publica 2005; 39(3):507-514.

9. Instituto Brasileiro de Geografia e Estatística (IBGE). Dados gerais e informações estatísticas da cidade de Bambuí.Rio de Janeiro: IBGE; 2010. [acessado 2011 out 4]. Disponível em: http://www.ibge.gov.br/cidadesat/topwindow.htm?1

10. Rios DFF, NMA Loreto MDS, Fiúza ALC. O programa bolsa-família em um contexto de cidades rurais: o caso de Bambuí, MG. Oikos Viçosa 2011; 22(2):150-170.

11. Prefeitura Municipal de Bambuí. Dados da História da Cidade. [acessado 2011 out 4]. Disponível em: http://www.bambui.mg.gov.br/

12. Uchôa E. Contribuições da Antropologia para uma Abordagem das Questões Relativas à Saúde do Idoso. Cad Saude Publica 2003, 19(3):849-853.

13. Corin E, Uchôa E, Bibeau G, Kouma-Re B. Articulation et variations des systèmes de signes, de sens et d'actions. Psychopathologie Africaine 1992; 24:183204.

14. Uchôa E, Vidal JM. Antropologia Médica: Elementos Conceituais e Metodológicos para uma Abordagem da Saúde e da Doença. Cad Saude Publica 1994; 10(4):497-504.

15. Brasil. Ministério da Saúde (MS). Conselho Nacional de Saúde. Resolução nº 196 de 10 de outubro de 1996. Diretrizes e Normas Regulamentadoras de Pesquisas Envolvendo Seres Humanos. Diário Oficial da União 1996; 16 out.
16. Debert GG. A dissolução da vida adulta e a juventude como valor. Horiz. antropol 2010; 34:49-70.

17. Mattéi JF. La dignité de la vieillesse et du handicap. In: Yves J. Vieillir handicapé ERES. Connaissances de la diversité. [S.1.]: Editions Eres; 2011. p. 169-181.

18. Lima-Costa MF, Facchini LA, Matos DL, Macinko J. Mudanças em dez anos das desigualdades sociais em saúde dos idosos brasileiros (1998-2008). Rev Saude Publica 2012; 46(Supl. 1):100-107.

19. Ricoeur P. Vivo até a Morte seguido de Fragmentos. São Paulo: Editora WMF Martins Fontes; 2012.

20. Bacqué M-F. Augmentation de la longevité, multiplication des deuils. Les nouveaux "vieux" sont aussi de grands endeuillés. Études sur la mort 2004; 126: 149-158.

21. Le Breton D. Anthropologie de la douleur. Paris: Ed. Métailié; 1995.

22. Moraes GVO. Influência do Saber Biomédico na Percepção da Relação Saúde/Doença/Incapacidade em Idosos da Comunidade [dissertação]. Belo Horizonte: Centro de Pesquisas René Rachou; 2012.

23. Clément J-P. Quelques considérations sur le deuil de la personne âgée. Études sur la mort 2009; 1(135): 33-39.

24. Rossi I. Culture palliative: pour anticiper et accueillir la mort. Revue Internationale de Soins Palliatifs 2010; 1(25):37-43.

25. Ribes G. De l'inconsolable à la veuve joyeuse. Gérontologie et Société 2000; 95:87-98.

26. Minayo MC, Meneghel SN, Cavalcante FG. Suicídio de homens idosos no Brasil. Cien Saude Colet 2012; 17(10):2665-2674.

27. Santos WJ, Giacomin KC, Pereira JK, Firmo JOA. O Enfrentamento da incapacidade funcional por idosos da comunidade de Bambuí: crença religiosa e descrença nos serviços públicos de saúde. Cien Saude Colet 2013; 18(8):2319-2328.

28. Giacomin K, Uchôa E, Lima-Costa MF. Projeto Bambuí: a experiência do cuidado domiciliário por esposas de idosos dependentes. Cad Saude Publica 2005; 21(5):1509-1518.

Artigo apresentado em 30/04/2013

Aprovado em 22/05/2013

Versão final apresentada em 05/06/2013 